\title{
Measuring judiciarization of people with mental illnesses
}

\author{
Oxana Mikhaylova ${ }^{1}\left[\right.$ ] Julia Naumova ${ }^{2} \oplus$
}

Accepted: 21 January 2022 / Published online: 2 March 2022

(C) The Author(s), under exclusive licence to Springer Nature B.V. 2022

\begin{abstract}
The judiciarization of the psychiatric subject is a two-sided process. It could antidiscriminate people with mental illnesses but, at the same time, it could potentially provoke pathologization of mental illnesses. Current methodologies proposed to measure this important and complicated process for people with mental illnesses do not allow analysis on multiple levels (the macro, meso, and micro). In this article, to fill this gap we propose a methodological strategy that helps to investigate judiciarization of people with mental illnesses on multiple levels at once. This approach is based on critical discourse analysis of legal documents and court decisions that feature people with the poor mental health. Namely, we suggest how to measure the level or degree of judiciarization, its geographical evenness, actors in the legal process, its dimensions (the law branches of its occurrence), and linguistic content. We applied this methodology in examining 1,243 legal documents and 327,311 court decisions that were issued by agents of the Russian law system. The research findings show that judiciarization levels in Russia have been rising over the years, moving away from stigmatizing those with mental illnesses and towards anti-discrimination. Our paper could be of interest to socio-legal researchers and social policy practitioners.
\end{abstract}

Keywords judiciarization · critical discourse analysis $\cdot$ legal discourse on mental health $\cdot$ Russia

\section{Introduction}

Judiciarization is a process that is characterized by an increase in the legal system's control of the rights and obligations of certain social groups (Pélisse, 2009). The judiciarization of vulnerable social groups such as children, migrants, and other minors is a thorny issue for scholars (Campbell et al., 2008; Commaille, 2021;

Oxana Mikhaylova

oxanamikhailova@gmail.com

1 Center for the Modern Childhood Research, HSE University, Moscow, Russia

2 HSE University, Moscow, Russia 
Pélisse, 2009). Current academic literature provides a limited spectrum of measures that could be used to examine the way the legal system increases control over people with mental illnesses on the macro, meso, and micro levels (Paradis-Gagné \& Jacob, 2020). This paper aims to address this gap. We suggest a methodology to measure this process using legal documents: laws, court decisions, and other acts.

We chose legal discourse in Russia because the current pathologization/anti-discrimination debate in Russia is controversial, and additional research is needed to understand which consequences of judiciarization currently prevail in the country (Kolpakova, 2019). Russia is a civil-law country, so Russian courts sometimes rely on precedents established by the nation's Supreme Court (Ghossoub \& Felthous, 2020). The provision of mental health services is the duty of local authorities, but the state still controls and coordinates it (Kolpakova, 2019).

The analysis that we carry out in this article is methodologically novel and therefore valuable for judiciarization research. In addition, our paper adds to the literature on the development of the Russian psychiatric system because, compared to previous papers on this topic, for example Kolpakova (2019), Morozov (2018), and Neznanov and Vasileva (2015), we examine the formal features of the production of legal documents in the historical context and analyze how people with poor mental health are treated at the textual level (linguistically). Investigating only one aspect of the legal discourse on mental health leads to an incomplete view and unreliable conclusions about the way the Russian legal system treats people with mental illness. Examining the three layers of judiciarization of people with poor mental health, as we do in this article, helps prevent reducing the multidimensional legal system to the sole level of social reality.

This article begins by describing the current state of research regarding the judiciarization of people with mental illness. Next, we describe our methodological approach and empirical data. Finally, we present and discuss the study's results.

\section{Theoretical and methodological principles for measuring judiciarization of people with mental illnesses}

Among mental health professionals and beyond, through the years there have been two competing discourses on mental illness (Bates et al., 2020; Bowen \& Lovell, 2021; Foucault \& Lagrange, 2006; Goffman, 1968; Monnapula-Mazabane \& Petersen, 2021; Riles et al., 2021; Tuliao, 2021; Vlasova, 2014). One of them pathologizes people who have mental health problems, and the other, on the contrary, represents a humanitarian turn towards anti-discrimination of this vulnerable social group.

The juridical institution is one of the institutions that has been contributing to this rivalry (Batastini et al., 2018; Simonsson et al., 2020; Blake \& Hatzenbuehler, 2019; Werner and Doron 2017). On the one hand, legal discourse on mental illnesses aims to guarantee access to treatment for economically and culturally diverse groups. On the other hand, this same discourse enables treatment provision for people who would otherwise not consider themselves to have mental illnesses, extends the power of state surveillance, and creates a double stigma-being both a criminal 
and mentally ill-decreasing opportunities for self-realization. Therefore, policymakers and scholars continue to be concerned about the potential pathologization of people with mental illnesses in the legal system. Furthermore, a constant analysis of the framing of mental health in legal discourse is needed to control the way mental illnesses are portrayed therein.

The research on the judiciarization of mental illnesses to date is informed by two major theoretical and methodological traditions: criminality and criminalization (Ballard \& Teasdale, 2016).

1. Criminality scholars explain the overrepresentation of people with mental illnesses in the state legal system by claiming that having mental health issues increases one's likelihood of committing a crime. In this case, the judiciarization is investigated by measuring the personal characteristics of people with a diagnosed mental illness accused of crimes and comparing them with their counterparts who have not been diagnosed with a mental illness (Hiday \& Moloney, 2014; Junginger et al., 2006; Skeem et al., 2011). This is the micro-level approach because the macro (systemic) factors of judiciarization of people with mental illnesses are not considered.

2. Criminalization researchers, on the contrary, argue that people with poor mental health enter the legal system due to systemic factors such as the deinstitutionalization of mental health care provision (Novak \& Engel, 2005; Schulenberg, 2016; Steury, 1991). In this case, the judiciarization is studied by examining the actions of the system agents - for example, police officers, juries, and advocates. This analysis is based on official statistics, observations, and interviews and could be considered the macro-level approach, since it does not account for the factors on the individual (micro level) that could contribute to the personal likelihood of facing the legal system.

Although the criminality perspective describes the judiciarization on the micro level and criminalization on the macro, no one has yet proposed an approach that considers both macro and micro levels of judiciarization. Moreover, these theoretical traditions do not explain judiciarization on the meso level. Meso-level factors are those that appear because of the macro and micro level functioning togetherfor example, when a person with a mental health condition has a higher probability of being punished than someone without mental health issues, not only because it is more difficult for her to follow strict legal rules due to her mental health condition, but also because lawyers are afraid of people with mental health illnesses and suppose that it is better to give them harsher punishments and isolate them from "healthy" society. Considering the current absence of a perspective that views judiciarization on all three levels, in this paper we suggest focusing on how macro-, meso-, and micro-level factors contribute to judiciarization. In the following section we present the main methodological and procedural aspects of this perspective. 

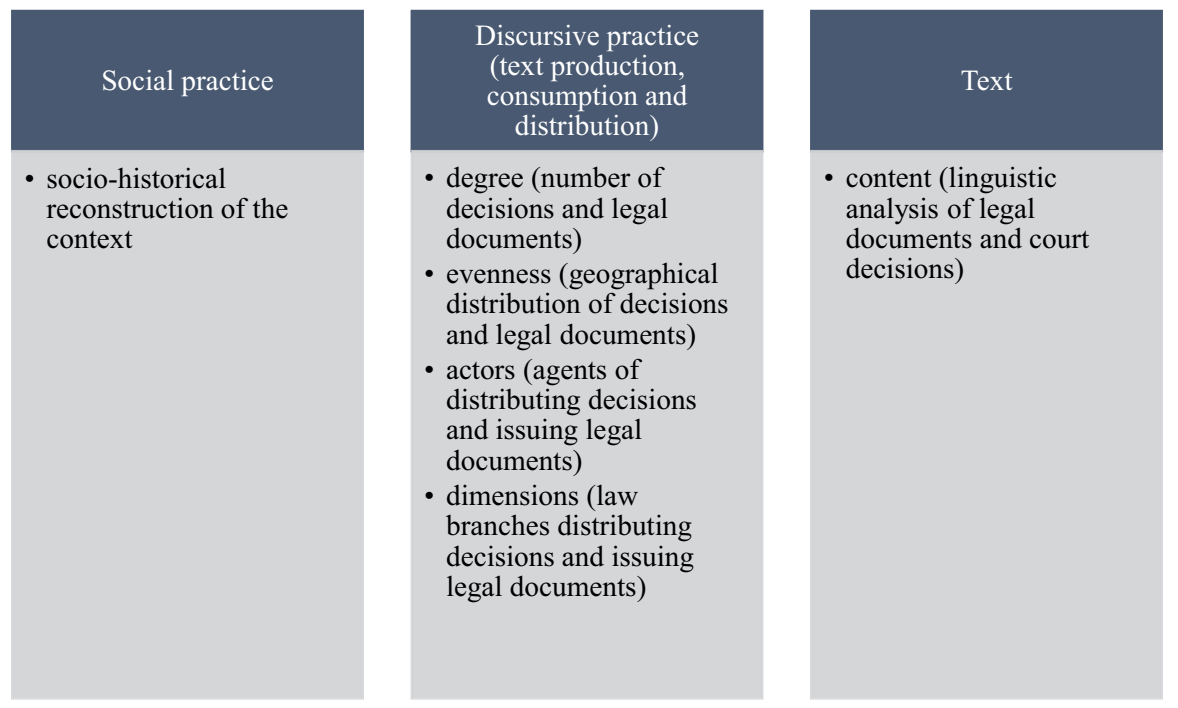

Fig. 1 Analytical plan

\section{Critical discourse analysis as a way to measure judiciarization}

To measure judiciarization we propose to use the three-levelled framework of critical discourse analysis (CDA) (Fairclough, 2001). This analytical approach has already been applied in the context of mental health and legal research (Joergensen \& Praestegaard, 2018; Jørgensen, Dahl, et al., 2020; Jørgensen, Praestegaard, et al., 2020; Jørgensen et al. 2020a, 2020b; Lassen et al., 2018; Jørgensen et al., 2021) but not to measure judiciarization. Fairclough (one of the founders of CDA) supposed that language could be employed as a way to exercise power, and to analyze how, he suggested to study speech in the context of its production (Jørgensen and Praestegaard 2018; Fairclough, 2007). This scholar distinguished between three main factors that contribute to the influence of language (spoken or written) on people. On the macro level, text's power is determined by the social practice in which it is included. On the meso level, its capacity to impact people depends on the discursive practice in which it is used (production and interpretation of the text). Finally, on the micro level, text's ability to manipulate personal actions is influenced by the vocabulary and grammar that are employed in it.

Applying CDA to the judiciarization of people with mental illnesses means that we look at three levels: 1) social practice, 2) discursive practice and 3) text (Fig. 1).

1. The level of social practice (macro level) is studied through reconstructing the socio-historical context in which the legal system and system of mental health services converge.

2. The level of discursive practice (meso level) is investigated based on court decisions and formal aspects of legal document production. 
3. The analysis of the number of legal documents produced in dynamic indicates changes in the degree of judiciarization of people with mental illnesses.

4. The distribution of locations of the court cases shows the degree of geographical evenness of the judiciarization.

5. The data on the governmental entities that published the documents demonstrates who in the legal system contributes to the judiciarization process.

6. Examining the types (dimensions) of judiciarization shows to what law branches belong judicial documents that feature people with mental illnesses.

7. Judiciarization in text (micro level) may be examined using topic modelling and quantitative content analysis of the court decisions and legal documents. The characteristics of the words employed to speak about psychiatry and topics related to mental illness reveal whether people with mental illnesses are characterized in a stigmatizing, neutral, or even destigmatizing manner linguistically. We named this indicator "content of judiciarization."

\section{Data}

CDA of judiciarization was applied to the Russian cultural context. This sociohistorical context was characterized based on previous academic literature that is devoted to the history and current state of the Russian system of providing mental health services and its relation to the legal system. To obtain the data for discursive practice and text analysis we used information from two public Russian legal databases: Gas Pravosudie ${ }^{1}$ and Consultant Plus. ${ }^{2}$

The court decisions database (Gas Pravosudie) includes records of trials. It is possible to retrieve information on who participated in the hearings, where the hearings were held, what charges were brought forward, and what legal documents were used in the court. The results of the hearings and the subjects of the trials are also made available.

The legal documents database (Consultant Plus) has the complete texts of the legal documents. It is possible to retrieve information about who issued the document, the type of document, whether it is still in force, and the changes that were made to the text over time.

To form the corpus of texts for the analysis, first we looked for documents in these databases that contained the text token "psychiatr*" or "psycholog*" to find results with the application of psychological or psychiatric expertise. After that, we read through all the retrieved court decisions and legal documents to verify that they touched upon people with mental illnesses. As a result, our analysis of discursive practice and text is based on 1,243 legal documents from Consultant Plus and 327,311 court decisions from Gas Pravosudie.

\footnotetext{
1 GAS RF "Pravosudie". https://bsr.sudrf.ru/bigs/portal.html. Accessed 11 October 2020.

2 Consultant Plus. http://www.consultant.ru. Accessed 11 October 2020.
} 


\section{Measures}

\section{Macro level (social practice)}

To reveal the context in which the production of legal documents and court decisions was made we reconstructed socio-historical features of the transformation of the legal system in Russia.

\section{Meso level (discursive practice)}

Degree of judiciarization of people with mental illnesses was investigated using the formal data on the publication of legal documents and court decisions. Namely, we calculated changes in the number of legal documents published.

Geographical evenness of judiciarization was analyzed based on the regional classification of court decisions.

The actors who contributed to the judiciarization were described by the computation of the shares that certain governmental entities had in the publication of legal documents and which courts (at which levels) published case decisions. The information on their involvement is provided for court decisions and legal documents automatically.

We studied the dimensions of judiciarization primarily using formal data analysis (classification of cases and legal documents by law branch, information produced automatically by the Consultant Plus and Gas Pravosudie databases). We computed the shares of criminal, administrative, civil, and procedural law among legal documents and court decisions.

\section{Micro level (text)}

We examined the content of judiciarization based on the categorization automatically created for the cases in Gas Pravosudie. This database groups the court decisions according to topic (for instance, "disputes over lands and housing"). We also calculated the percentages of certain topics among court decisions.

There were no automatically classified topics for the legal documents, so we performed topic modelling (Hornik \& Grün, 2011). For this analytical procedure, we preliminarily lemmatized the texts and removed punctuation, personal pronouns, and other noise words. A number of authors have used this method of data analysis for legal documents (Carter, Brown, and Rahmani 2016; Gotardo, 2018) because legal data is usually voluminous and would require years for manual processing.

This investigation of the topics in legal documents and court decisions was complemented by quantitative content analysis. We researched the words most frequently used in the cases and legal documents to reveal whether there were words that pathologized mental illness or whether the language in these documents was anti-discriminatory or neutral. We supposed that the more negative 
evaluations and medical terminology both corpora contain, the more they pathologize people with the poor mental health conditions.

\section{Analytical findings}

\section{Macro level (social practice)}

The use of psychiatric forces as a means of political abuse by the Russian government in the twentieth century is known worldwide (Faraone, 1982; Young-Anawaty, 1978). Communist psychiatry, apart from being a form of political repression, was characterized as centralized in its policymaking, Pavlovian and anti-Freudian, occupationally therapeutic, and isolated from the Western community of psychiatrists (Raikhel \& Bemme, 2016). However, the Russian system of public health has significantly changed since those times (Kolpakova, 2019; Morozov, 2018; Neznanov \& Vasileva, 2015; Polubinskaya, 2000). Despite this, the historical memory of this period has not disappeared and still underlies some clinical practices (Raikhel \& Bemme, 2016) and explains public anti-psychiatric attitudes in Russia (Poloshij \& Saposhnikova, 2001).

New bioethical guidelines and legislation were created during the transformation of the Russian mental health system, namely, a 1992 law that guaranteed the right to psychiatric care (Krasnov \& Gurovich, 2012). Moreover, a push for deinstitutionalization reduced the number of psychiatric hospital beds (Shek \& Ilkka, 2017). Some features of personal development and of the therapeutic turn (Madsen, 2014) in Russia started to become noticeable even in Soviet times: Advice and self-help literature became fashionable, alongside yoga classes and self-improvement practices. However, these trends were rooted in the disciplinary idea of self-development and pedagogy of the good citizen (Raikhel \& Bemme, 2016).

The therapeutic turn in Russian society is still in process: New media content about psychiatry and people with mental illnesses is appearing, and neurodiversity movements have started to blossom (author removed, 2022). Western ideas behind personal consumption of psychiatric culture have become popular in economically developed Russian communities. This means that people not only use psychology as a means of self-improvement but also are slowly starting to trust psychiatrists and to consider their services an essential part of ordinary life. It is important to highlight that these changes related to psychiatry mostly occur among people with high income levels; most Russian citizens still treat psychiatry with suspicion, as the polls show. ${ }^{3}$

At the same time, studies have reported that there are still serious problems with the provision of psychiatric help for Russian citizens, e.g. (Krasnov \& Gurovich, 2012). Some are related to the technological underdevelopment of the Russian psychiatric system, and others to the shortage of well-qualified specialists to provide

\footnotetext{
${ }^{3}$ Psychological help and psychologists (FOM). https://fom.ru/Obraz-zhizni/14183. Accessed 11 Oct 2020.
} 


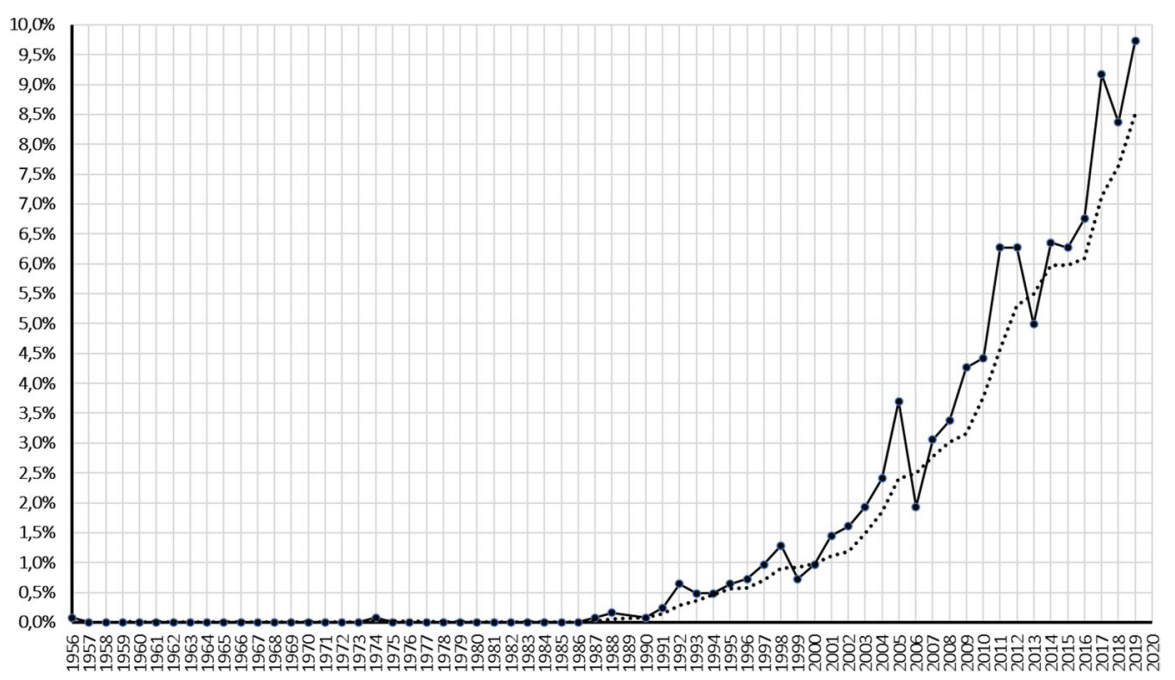

Fig. 2 Legal document publication dynamic. Dotted line: Four-year moving average. Source: Consultant Plus (https://www.consultant.ru/)

high-quality help. Further problems include a lack of coordination between psychiatric and medical institutions and the hyper-centralization of psychiatric services. Scholars mainly link these difficulties to the overhaul of the psychiatric system in Russia alongside the multiple economic crises in Russia in the'90s (Morozov, 2018; Raikhel \& Bemme, 2016). In addition, Kolpakova (2019) analyzed the policy documents in Russia and the scientific literature and showed that, although Russia is moving towards the European models of mental health care, the topics of social inclusion, stigma, and independent patient living remain underdeveloped. The voices and opinions of patients, their families, and non-governmental organizations are not heeded during the development of legislation and policymaking.

From this brief historical overview, we can conclude that, through the years, the judiciarization of people with mental illnesses in Russia has been increasing. As the provision of mental health is controlled by the municipal government, we can expect to find geographical inequality in this judiciarization. In terms of the content of judiciarization, on the one hand, the transformation of the mental health system in Russia could have resulted in a humanized legal discourse on mental health. On the other hand, Soviet heritage and the structural difficulties in the transformation of the Russian mental health system could have led to the pathologization of mental health in juridical discourse.

\section{Meso level (discursive practices)}

\section{Degree}

We analyzed only those legal documents $(1,243)$ that were in force until 2020 . They were issued between 1956 and 2019. Figure 2 shows that most of the documents 
examined were published between 2010 and 2019 (68.6\%). There were also documents in our database that were created much earlier.

In general, the dynamics of the judiciarization of people with poor mental health at the level of legal documents in Russia are erratic. However, the moving average approximation ${ }^{4}$ indicates that their publication has been rising over the years and that this trend will likely continue in the future. The peaks in the number of the legal documents were in 1998, 2005, 2011, 2012, 2014 and 2017.

The increase in legal discourse production in 1998, according to its content, can be explained by this time being the beginning of the convergence of the Russian system of medical classification and the world standards of health care provision. In addition, in 1998, numerous criminal laws were renewed. In turn, the next peak of the publication of legal documents in 2005 can also be attributed to the issue of new documentation that regulated the work of medical specialists, when the constitutional court produced some important decisions for cases that violated mental health patients' rights. In sum, the peaks in the production of legal documents in 1998 and 2005 were mostly connected to transformations within the Russian medical system.

In comparison, changes in the law-making agenda in 2011 and 2012 were related to the country's realignment of military forces. Namely, the rise in the number of legal documents in 2011 and 2012 can partly be explained by the police reform. New regulations were needed for this agency, and regional legislation was created for developing municipal forces that work in the fields of emergencies and natural disasters.

The next increase in legal document production in 2014 was again connected to the development of the Russian medical system. Nevertheless, this time the focus was on modernizing the educational standards for students specializing in psychiatry, medicine, and narcology. In addition, the administrative apparatus of the country continued transforming, and laws were issued on the mental health care in federal prisons.

The last peak in judiciarization of people with poor mental health was in 2017. It was caused by the aim to diversify juridical regimes for people who deal with psychiatric institutions in Russia. For example, several regulatory measures were introduced to defend the rights of children with mental disabilities. In addition, the spheres in which the mental health of an individual is important were widened: More legal documents were created on workers' mental health through a significant transformation in labor law.

Our database of court decisions (cases), in contrast to the legal document corpus, contains 327,311 records, all of which were issued from 2010 to 2019 (Fig. 3). We chose this time period because cases started being made public in Russia in 2010, and in 2020, a new version of the Russian Constitution came into force, so we decided to exclude new regulations that could influence the corpus and its consistency.

\footnotetext{
${ }^{4}$ Moving average approximation helps smooth the time series data (Hunter 1986). Using this statistical correction method, we can consider random effects and other measurement errors that often arise in temporal data.
} 




Fig. 3 Case publication dynamic. Dotted line: moving average (four years). Source: GAS RF "Pravosudie" (https://bsr.sudrf.ru/bigs/portal.html/)

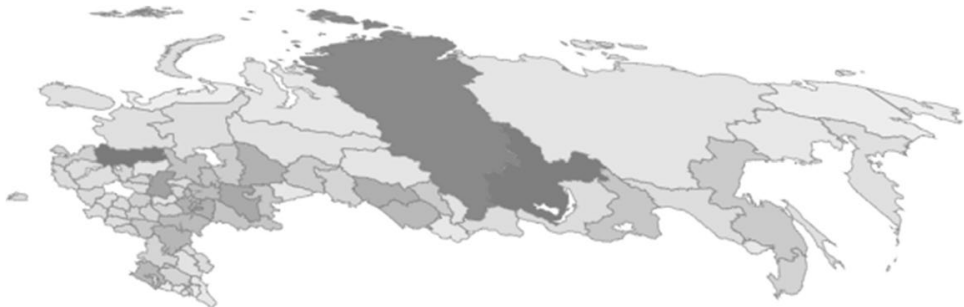

Fig. 4 Geographical distribution of judicial cases. Source: GAS RF "Pravosudie" (https://bsr.sudrf.ru/ bigs/portal.html/)

There has been an upward trend in the number of court decisions and legal documents, and $96 \%$ of all analyzed cases were published from 2016 to 2019. The moving average time series correction that we conducted on the cases showed that there were no noticeable peaks in the publication of court decisions, yet the number of cases has been rising almost every year.

Of course, it is important to explain the changes in the publication of court decisions as we did earlier with legal documents. Longitudinal topic modelling analysis would have been helpful to understand the connection between the level of people with poor mental health judiciarization and its content. However, the current corpus of court decisions has too few records for such an examination, so we decided not to apply this textual data analysis method. We hope that when more cases are issued in the future, time series analytics for Russian cases on mental health topics will be possible. 


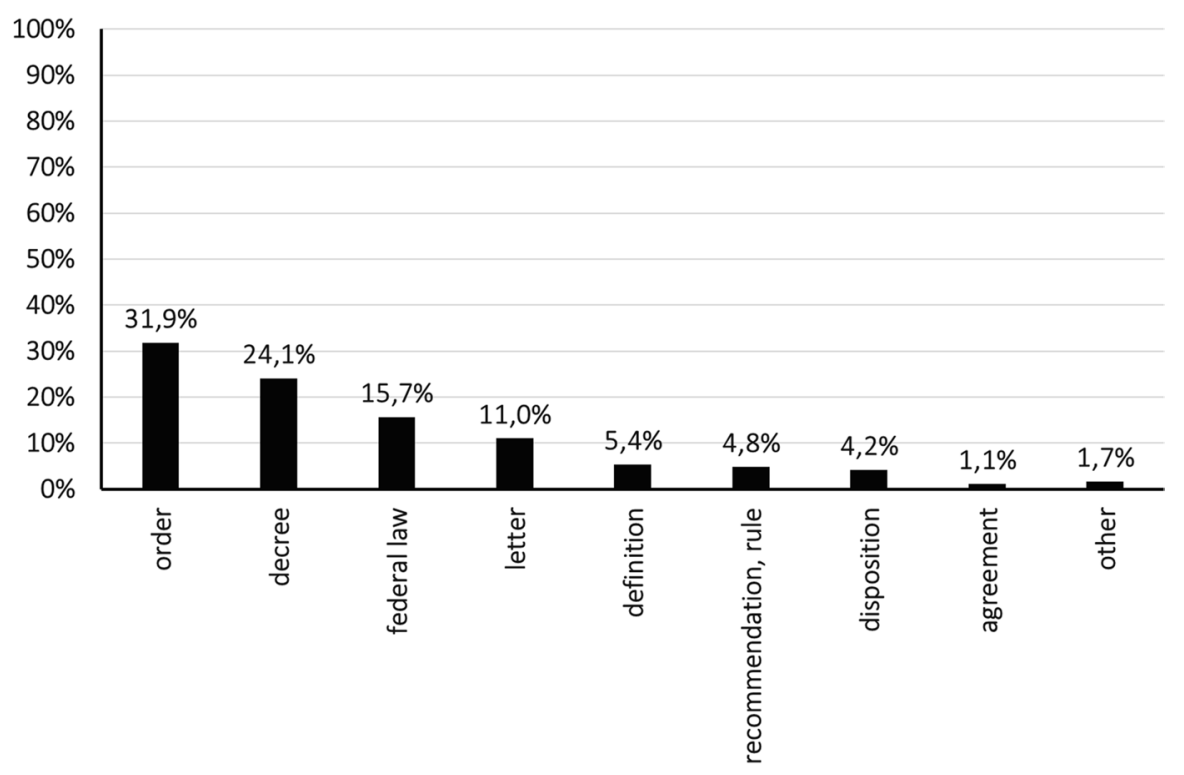

Fig. 5 Types of juridical documents on mental health in Russia. Source: Consultant Plus (https://www. consultant.ru/)

\section{Evenness}

Court decisions on mental health are not spread evenly geographically (Fig. 4). This can be partly explained by the geographical distribution of the population in Russia and the number of courts in each region. However, even with such corrections, there are two region leaders in the number of court decisions on people with mental illnesses. These are Vologda Oblast (5\%) and Irkutsk Oblast (4.8\%).

Irkutsk Oblast leads its region in the number of crimes committed in Russia. It held second through tenth place in the ranking of regions based on unlawful acts committed per 100,000 people during the previous decade..$^{5}$ Most of the court decisions on mental health that have been issued in this region are related to theft $(70 \%)$ and drug production, consumption, or exchange (15\%).

Vologda Oblast, in turn, is one of the region's leaders in minor crimes and murders per 100,000 people (holding ranks 8-20 in these categories). Most of the court decisions that have been published on mental health in this region are devoted to utility payments $(30 \%)$ and loans $(15 \%)$. In sum, because both regions are in a difficult criminogenic situation, it is not surprising that both are leaders in the number of cases that mention people with mental illness.

\footnotetext{
${ }^{5}$ Portal of Russian crime statistics. http://crimestat.ru/regions_chart_population. Accessed 11 Oct 2020.
} 


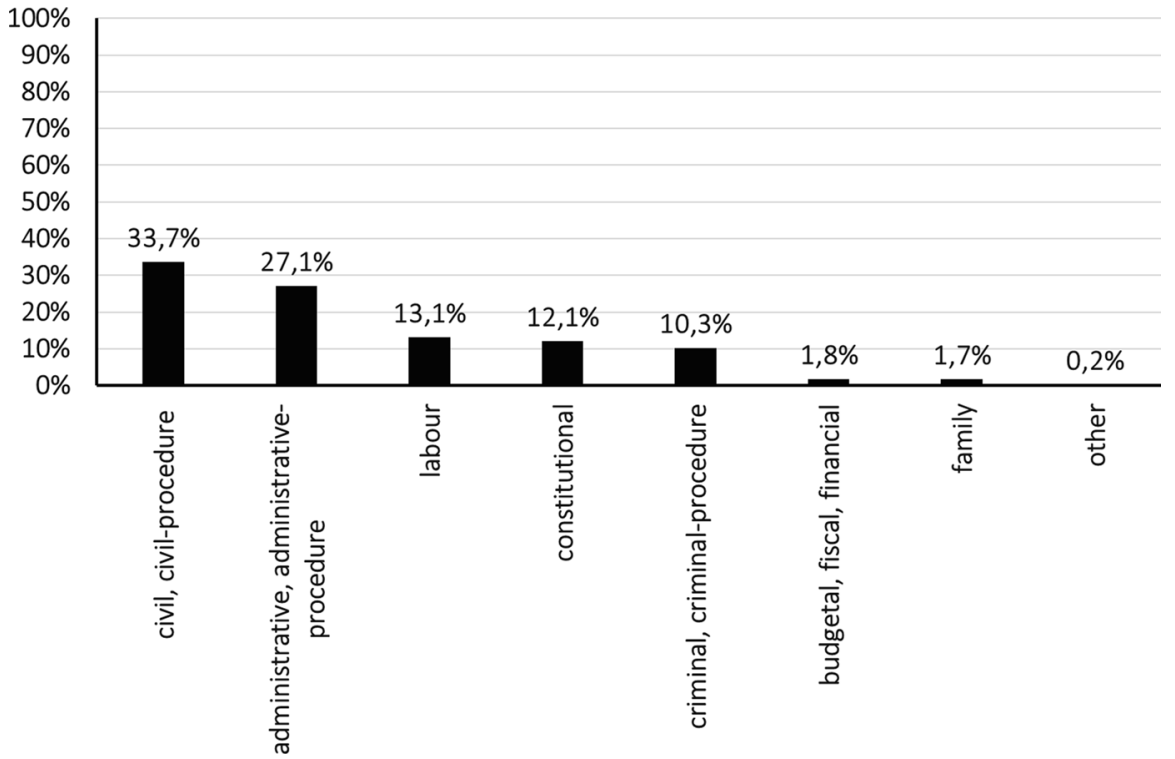

Fig. 6 Areas of law in Russian legal documents. Source: Consultant Plus (https://www.consultant.ru)

\section{Actors}

The Ministry of Health and Social Development (18\%), courts (16\%), and government (exercises executive power in Russia). (10\%) prevail in the number of legal documents produced on people with poor mental health in Russia. Figure 4 shows that the greatest quantity of documents were orders $(31.9 \%)$ and decrees $(24.1 \%)$. Both these observations demonstrate that most of the legal documents on people with poor mental health in Russia are civil and administrative (Fig. 5).

Regarding the courts that produced decisions on the people with poor mental health, most cases in the corpus were published by district, municipal, and interdistrict courts (71\%). This means that decisions on people's mental health are processed by Russia's mid-level court system.

\section{Dimensions}

Most of the legal documents refer to civil (33.7\%) and administrative $(21.7 \%)$ law (Fig. 6). The least common are legal documents related to family (1.7\%) and financial (1.8\%) law. This indicates that children, the finances of people with mental illnesses, and those who care for people diagnosed with mental illnesses could currently be under-protected or their legal position less nuanced in Russian legal discourse.

In addition, such dimensions of judiciarization could suggest that juridical discourse on mental health in Russia is now mostly regulated by civil and 


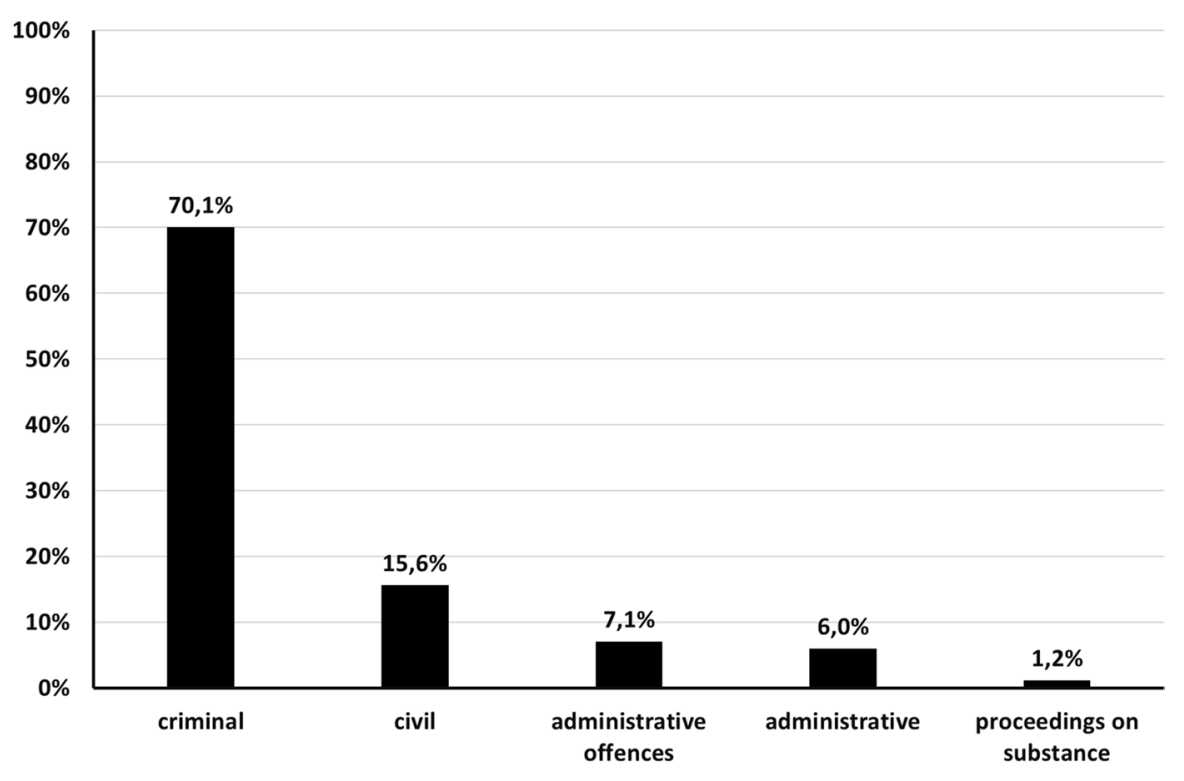

Fig. 7 Areas of law in court decisions. Source: GAS RF "Pravosudie" (https://bsr.sudrf.ru/bigs/portal. $\mathrm{html} /$ )

administrative norms. This conclusion corresponds with the observations formed based on the analysis of the actors of judiciarization. We believe that the dimensions of judiciarization of people with poor mental health in Russia could change in the future because, lately, as mentioned earlier, the spheres in which mental health is considered an important issue in this country have started to widen.

Court cases, in comparison, are mostly criminal (70.1\%) (Fig. 7). Although at the level of legislation people with poor mental health are mostly discussed in the noncrime dimension, at the level of law implementation, criminal law framings prevail.

\section{Micro level (text)}

\section{Content}

Topics Table 1 provides the 16 topics generated by a topic model. The tokens for each topic are listed in descending order, starting with the highest-weighted words in the distribution. The topics in the table are ranked according to their prevalence in the documents. The topic labels were generated automatically ${ }^{6}$ and slightly corrected during the discussion between researchers because numerous publications mention that automatic topic labelling is not yet perfectly developed.

\footnotetext{
${ }^{6}$ More about automatic topic allocation can be found in Lau et al. (2011).
} 


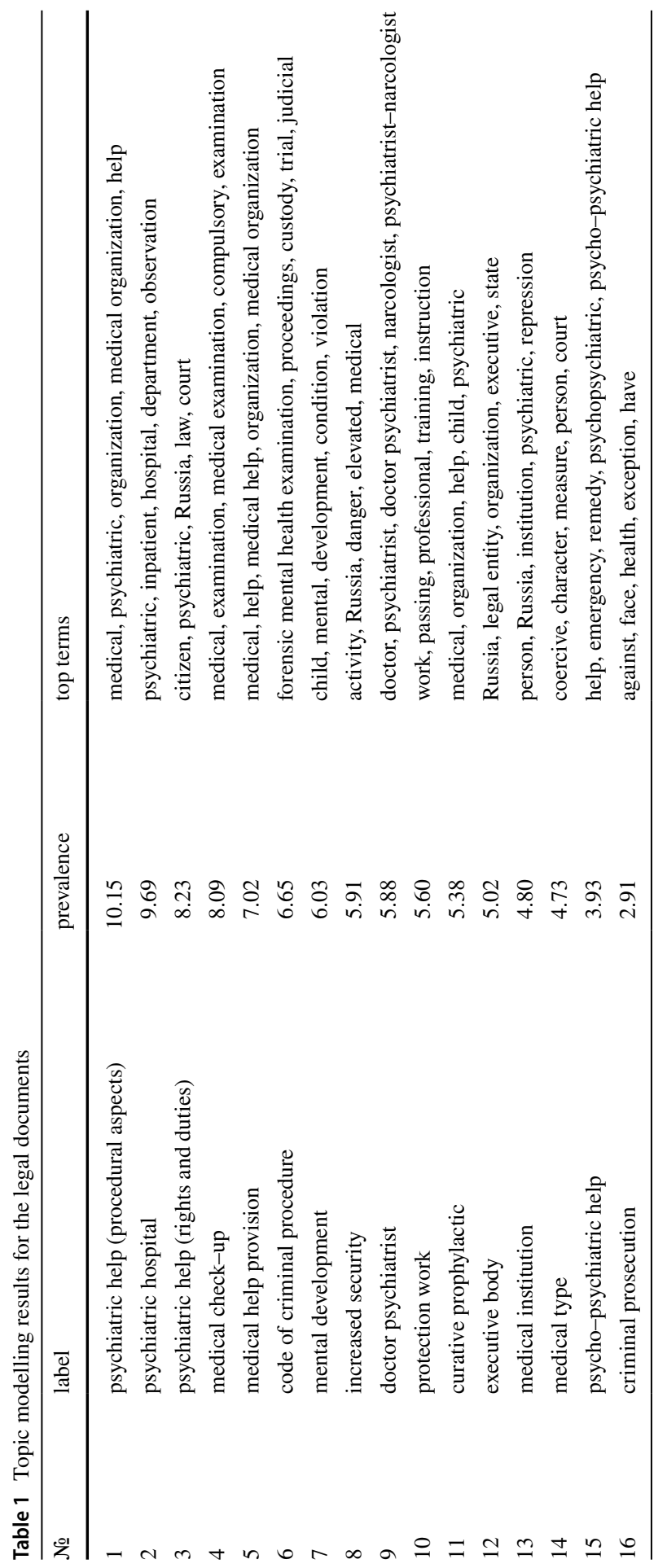


Table 1 shows that the prevalent topic is related to psychiatric help and the technological aspects of its provision. The second most prevalent topic is associated with psychiatric in-patient facilities and the third with the rights of people in medical facilities. The least prevalent topic is related to criminal measures for people who committed a crime while being mentally ill.

This topic distribution shows that Russian legislation devoted to people with poor mental health is mostly focused on providing help for them and on the rights of medical workers and those in facilities as patients. Meanwhile, the least commonly addressed issue in the Russian legal documents currently in force is criminal justice concerning the people with mental illnesses.

Compared to the content of legal documents (Table 1), the topic distribution of court decisions (Table 2) — generated based on the automatic case classification of Gas Pravosudie-demonstrates that the most prevalent topics connected with judiciarizing people with poor mental health in Russia in legal practice are thefts, robberies, and actions related to the selling, consumption, and exchange of drugs and alcohol. The least prevalent topics are moral damage compensation, non-profit unlicensed operations, and sanctions on parents for non-fulfillment or improper fulfillment of their obligations regarding the care and upbringing of juveniles.

Vocabulary Figure 8 exhibits that, in legal documents related to people with poor mental health in Russia, the most frequently used words are connected to workrelated psychiatric examinations such as "work," "certification," and those related to the provision of psychiatric care ("in-patient" and "examination"). Additionally, names of medical check-ups that are obligatory in the court setting are often mentioned in these legislations, like "forensic mental health examination."

In comparison, the frequency figures for words employed in court decision texts show that the topic of obligatory psychiatric inspection prevails. This topic is indicated by such words as "compulsory," "psychiatric examination," and "forensic mental health examinations" and "work-related examinations", which are mentioned less commonly (Fig. 9). The quality of psychiatric help provision is discussed much less compared to in legal documents. This shows that people with mental illnesses are represented in court decisions mostly as those who committed a crime. Mental state is mentioned in these texts in connection with an assessment that must be performed to determine how the person should be punished. However, the rights violations experienced by these people appear less in court discourse.

We did not find words in the legal documents and court decision texts that could dehumanize or stigmatize mental illness. In both types of text, people with poor mental health are mostly referenced in medical settings and in connection with controlling operations. 


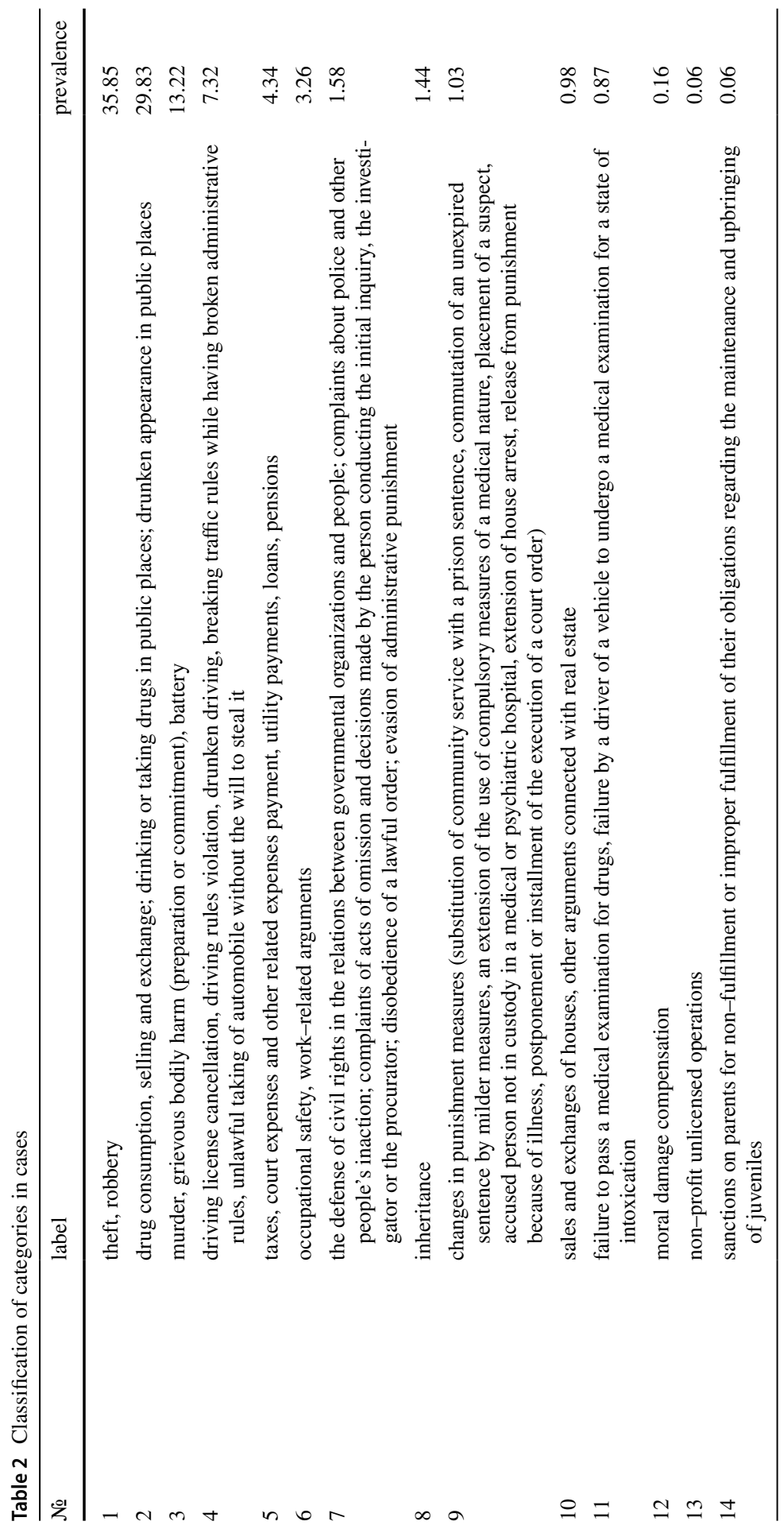




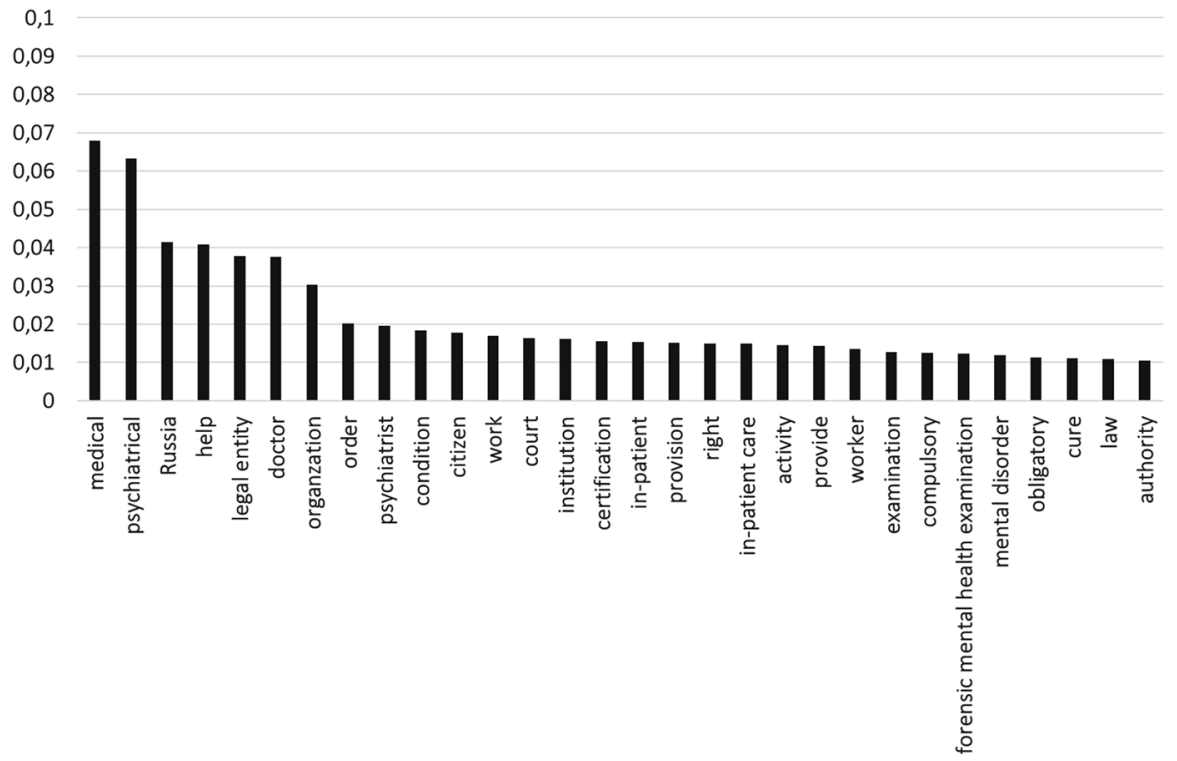

Fig. 8 Most frequent words in legal documents. The frequency is divided by the number of words in the documents. Source: Consultant Plus (https://www.consultant.ru/)

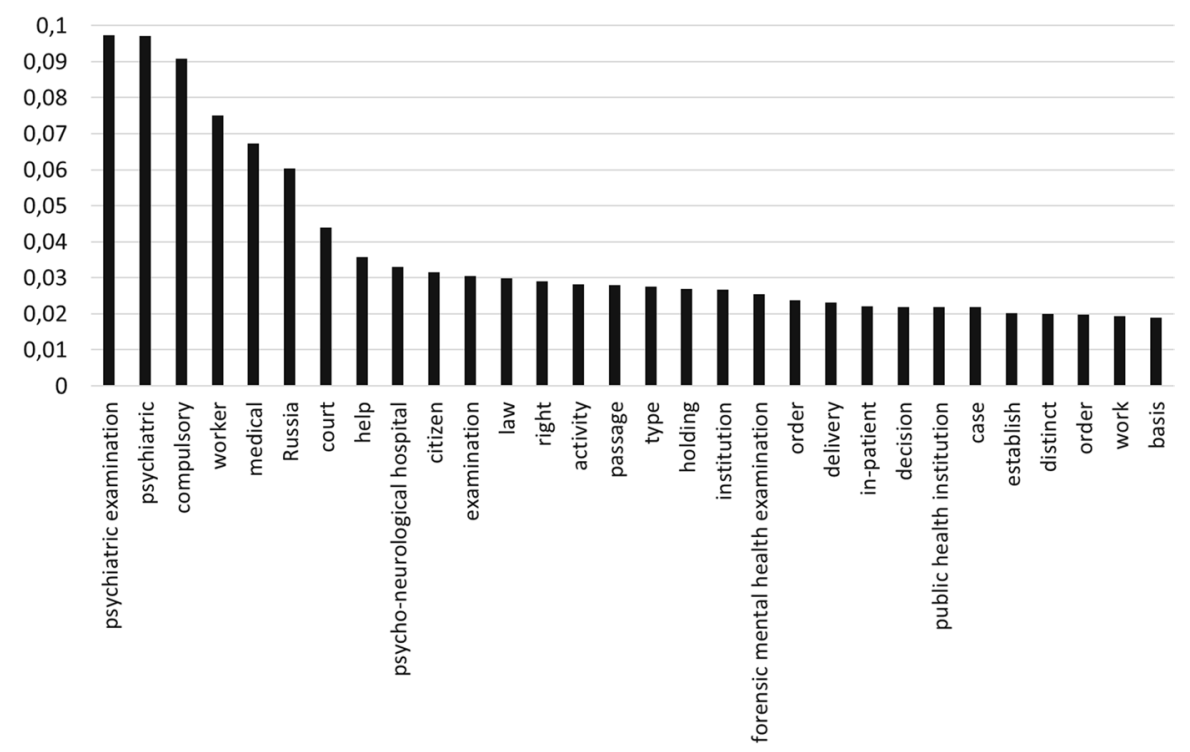

Fig. 9 Most frequent words in court decisions. The frequency is divided by the number of words in the documents. Source: GAS RF "Pravosudie" (https://bsr.sudrf.ru/bigs/portal.html/) 


\section{Discussion and conclusion}

In this paper, we propose a methodological approach that could be used to measure the judiciarization of the mental illnesses on the basis of textual legal discourse (legal documents and court decisions). Previous approaches to measuring this phenomenon did not account for three types of factors that increase the legal control of people with poor mental health. To overcome this limitation, we used Fairclough's discourse analysis scheme (chain investigation: text, discourse practice, and social practice). We researched the level of judiciarization, the evenness of this process, the actors involved, the dimensions, and the content. Our analysis showed that judiciarization levels in Russia have been rising over the years, with movement towards anti-discrimination.

Kolpakova's (2019) breakdown of policy changes over time seems limited and do not covers all aspects of the development of providing care in the mental health system. Kolpakova does not address the changes associated with the transformation of the Russian military that needed to be supplemented with renewed mental health legislation.

We deliberately excluded from the analysis legal documents that were not in force. However, it could be fruitful to investigate which legal documents the system omitted (490 documents in total). They were implemented between 1959 and 2019. The legal documents that were no longer in force were mostly connected with governmental management $(26 \%)$, medical help provision and maintenance (29\%), finance management (19\%), and labor relations (19\%). The distribution of the juridical discourse on mental health that was no longer in force demonstrates that although some managerial aspects changed the core constitutional laws and values, they only changed them slightly. This means that there is room for transformation, which is probably taking place now, during the process of correcting the Constitution.

The judiciarization levels are unevenly distributed in Russia, as are the crime levels. This aspect of mental health provision is overlooked in the literature on Russian psychiatry and the legal system. It needs to be problematized because the uneven allocation of resources in the country potentially contributes to tensions and conflicts between citizens living in different parts of the country. Notably, at the level of legal documents, the condition of people with mental illnesses is regulated by mostly civil and administrative actors, especially the Ministry of Health. In terms of the dimensions of judiciarization, we found that people with poor mental health are judiciarized in connection with civil law in legal documents and with criminal law in court decisions. This demonstrates the persistence of the disconnect between legal document production and application-semiosis and praxis, as described in the literature (Kolpakova, 2019; Raikhel \& Bemme, 2016).

From examining judiciarization content, we can conclude that the prevalence of topics related to judiciarization differs between legal documents and cases. In legal documents, people with poor mental health are mostly discussed in connection with psychiatric help provision, whereas in cases the topics of theft, robbery, 
drugs, and alcohol consumption prevail. This difference corresponds with the results of the dimensions analysis and shows that the area of people with poor mental health in connection with crimes is probably underregulated and that the rights of people with mental health issues are underdefended in courts. The topics of stigmatization and social inclusion are definitely still underrepresented in the legal discourse, as Kolpakova (2019) found at the level of policy documents. Because her research was made based on data released before 2012, we can see that this problem still exists in Russia. However, we hope that, with the publication of the new version of the Constitution, these topics will be much more pronounced in both legal documents and legal decisions in the near future.

The language that is employed in the discourse of both legal documents and court decisions has no evaluative constructions. However, words connected with the medical sphere like "check-up," "medical," and "hospital" are frequently used in these texts, which indicates that judiciarized people with poor mental health are not pathologized but highly medicalized.

Overall, we think that the future transformation of Russian mental health legislation and judicial practices will continue to be very slow and that it will be difficult for Russia to completely dispose of communist psychiatry, despite improvements in constitutional law in the near future, mainly due to the economic crisis that could happen after COVID-19. This is because the lack of financial support for the mental health system in Russia has been fixed in the past, influencing the system's wellbeing (Raikhel \& Bemme, 2016).

\section{Methodological discussion}

The proposed approach was easy to implement in Russia because there are publicly available databases of legal documents and cases. However, it could pose problems in countries where the system of legal data collection and storage is not as developed. At the same time, both databases that we used provide only a macro perspective. Because we analyzed secondary data, we could not be sure of the way these data were collected. This concern is especially important for cases. Also, for this study, we were unable to conduct a time series analysis of the judicial decisions because of the short publication period. However, in the future it will be possible to analyze these decisions dynamically. In addition, to use the methodology proposed in this paper and be able to interpret all of the indicators of judiciarization, one must be familiar with the country's legal system and its history of and social attitudes towards mental health.

To conclude, the analytical capacity of the approach suggested in this paper to measure judiciarization through texts highly depends on the quality and content of the databases of legal documents and court decisions that exist in the chosen country. In the future, we think that such an approach could be complemented by an ultra-microanalysis of the discourse on the people with mental illnesses. This could be done, for example, through examining the communication about mental illnesses between legal agents. Also, our approach could be tested on the discourse of countries that have different legal systems from Russia to evaluate whether there are traits 
of legal systems that should be considered while measuring the judiciarization of people with mental illnesses through texts.

Acknowledgements We would like to thank HSE University Bachelor students (Stepanova G., Ozkyan M. and Kabanov V.) for their help with the data gathering on the preliminary stage of this project and our scientific advisor A. Bykov, whose comments helped to make this paper better.

Funding This research was funded by the Center of Student Academic Development (HSE University).

\section{Declarations}

Competing Interests The authors have no competing interests to declare.

\section{References}

Ballard, E., Teasdale, B. (2016) Reconsidering the Criminalization Debate: An Examination of the Predictors of Arrest Among People With Major Mental Disorders. Criminal Justice Policy Review, 27 (1). SAGE Publications Inc: 22-45. 10/ghq4d7.

Batastini, Ashley B., Michael E. Lester, and R. Alan Thompson. (2018) Mental Illness in the Eyes of the Law: Examining Perceptions of Stigma among Judges and Attorneys. Psychology, Crime \& Law, 24 (7): 673-686. 10/ghq4mr.

Bates, S., Andrew J. De Leonardis, Patrick W. Corrigan, and Gregory S. Chasson (2020) Buried in Stigma: Experimental Investigation of the Impact of Hoarding Depictions in Reality Television on Public Perception. Journal of Obsessive-Compulsive and Related Disorders, 26 (July): 100538. 10/ gm3rzw.

Blake, V.K., Hatzenbuehler, M.L (2019). Legal Remedies to Address Stigma-Based Health Inequalities in the United States: Challenges and Opportunities. The Milbank Quarterly, 97 (2): 480-504. 10/ gm3r2b.

Bowen, M., Lovell, A. (2021) Stigma: The Representation of Mental Health in UK Newspaper Twitter Feeds. Journal of Mental Health, 30 (4). Routledge: 424-430. 10/gm3rzg.

Campbell, Angela, Mairi Springate, and Nico Trocmé. (2008) Legislation's Influence on Judiciarization: Examining the Effects of Statutory Structure and Language on Rates of Court Use in Child Welfare Contexts. Windsor Yearbook of Access to Justice, 26 (2): 354. 10/gm3r2q.

Carter, D.J., Brown, J., Rahmani, A. (2016) Reading the High Court at a Distance: Topic Modelling the Legal Subject Matter and Judicial Activity of the High Court of Australia, 1903-2015. UNSWLJ 39. HeinOnline: 1300.

Commaille, J. (2021) La Judiciarisation. Une Nouvelle Économie de La Légalité Face Au Social et Au Politique.

Fairclough, N. (2001). Critical Discourse Analysis as a Method in Social Scientific Research. Methods of Critical Discourse Analysis, 5(11), 121-138.

Fairclough, N. (2007) Discourse and Contemporary Social Change. Vol. 54. Peter Lang.

Faraone, S. (1982) Psychiatry and Political Repression in the Soviet Union. American Psychologist 37 (10). US: American Psychological Association: 1105. 10/cvqt5d.

Foucault, M., Lagrange J (2006) Psychiatric Power: Lectures at the Collège de France, 1973-74. Basingstoke, Hampshire [England] ; New York: Palgrave Macmillan.

Ghossoub, E., Felthous, A.R. (2020) Mental Illness and the Lebanese Criminal Justice System: Practices and Challenges. International Journal of Law and Psychiatry, 71 (July): 101604. 10/ghq4fp.

Goffman, E. (1968) Asylums: Essays on the Social Situation of Mental Patients and Other Inmates. AldineTransaction.

Gotardo, M. A. (2018). Topic Modelling of Online Child Pornography Documents. International Journal of Social Science and Economic Research, 3(2), 505-521.

Hiday, V.A., Moloney, ME. (2014) Mental Illness and the Criminal Justice System. The Wiley Blackwell Encyclopedia of Health, Illness, Behavior, and Society. Wiley Online Library, 1-5. 10/ghq4fb. 
Hornik, K., Grün, B. (2011) Topicmodels: An R Package for Fitting Topic Models. Journal of Statistical Software, 40 (13). American Statistical Association: 1-30.

Joergensen, K., \& Praestegaard, J. (2018). Patient Participation as Discursive Practice-A Critical Discourse Analysis of Danish Mental Healthcare. Nursing Inquiry, 25(2), e12218. https://doi.org/10. 1111/nin. 12218

Jørgensen, K., Praestegaard, J., Holen, M. (2020b) The Conditions of Possibilities for Recovery: A Critical Discourse Analysis in a Danish Psychiatric Context. Journal of Clinical Nursing, 29 (15-16): 3012-3024. 10/gm32hk.

Jørgensen, K., Rasmussen, T., Hansen, M, Andreasson, K., Karlsson, B. (2021) User Involvement in the Handover between Mental Health Hospitals and Community Mental Health: A Critical Discourse Analysis. International Journal of Environmental Research and Public Health, 18 (7): $3352.10 /$ gm32h3.

Jørgensen, K., Dahl, M.B., Frederiksen, J.. (2020a). Coherence in Intersectoral Collaboration between Psychiatric Centres and Community Mental Healthcare: A Critical Discourse Analysis. Nordic Journal of Nursing Research, 40 (3). SAGE Publications Ltd: 130-141. doi:10/gm32hn.

Junginger, J., Claypoole, K., Laygo, R., Crisanti, A.. (2006) Effects of Serious Mental Illness and Substance Abuse on Criminal Offenses. Psychiatric Services, 57 (6). Am Psychiatric Assoc: 879-882. 10/ghq4dh.

Kolpakova, S.V. (2019) A Journey through Russian Mental Health Care: A Review and Evaluation. International Journal of Mental Health, 48 (2). Taylor \& Francis: 106-132. 10/ghq4fk.

Krasnov, V., Gurovich, I. (2012) History and Current Condition of Russian Psychiatry. International Review of Psychiatry, 24 (4). Taylor \& Francis: 328-333. 10/ghq4fc.

Lassen, I., Ottesen, A.M., Strunck, J. (2018) Health Care Policy at a Crossroads? A Discursive Study of Patient Agency in National Health Quality Strategies between 1993 and 2015. Nursing Inquiry, 25 (4): e12252. 10/gfg276.

Lau, J.H., Grieser, K., Newman, D., Baldwin, T. (2011) Automatic Labelling of Topic Models. In, $1536-1545$.

Madsen, O.J. (2014) The Therapeutic Turn: How Psychology Altered Western Culture. Routledge.

Monnapula-Mazabane, P., Petersen, I. (2021) Mental Health Stigma Experiences among Caregivers and Service Users in South Africa: A Qualitative Investigation. Current Psychology, August. 10/gm3rzt.

Morozov, P.V. (2018) The Evolution of Psychiatry in Russia. International Journal of Culture and Mental Health, 11 (1): 1-9. 10/gght8d.

Neznanov, N.G., Vasileva, V. (2015) Legal Regulation of Mental Healthcare Provision in Russia. BJPsych International 12 (1). Cambridge University Press: 17-18. 10/ghq4 gg.

Novak, K.J., Engel, R.S. (2005) Disentangling the Influence of Suspects' Demeanor and Mental Disorder on Arrest. Policing: An International Journal of Police Strategies \& Management. Emerald Group Publishing Limited. 10/bqh6gb.

Paradis-Gagné, E., Jacob, J.D. (2020) Judiciarization of People Suffering from Mental Illness: A Critical Analysis of the Psychiatric-Judicial Interface. Journal of Psychiatric and Mental Health Nursing n/a (n/a). 10/ghq4fj.

Pélisse, J. (2009) Judiciarisation Ou Juridicisation? Politix, no. 2. De Boeck Supérieur: 73-96. 10/frmsgj.

Poloshij, B., Saposhnikova, I. (2001) Psychiatric Reform in Russia. Acta Psychiatrica Scandinavica 104. Wiley Online Library: 56-62. 10/cxhdsh.

Polubinskaya, S.V. (2000) Reform in Psychiatry in Post-Soviet Countries. Acta Psychiatrica Scandinavica 101 (399). Wiley Online Library: 106-108. 10/bvqcjx.

Raikhel, E., Bemme, D. (2016) Postsocialism, the Psy-Ences and Mental Health. Transcultural Psychiatry 53 (2). Sage Publications Sage UK: London, England: 151-175. 10/ghq4fm.

Riles, J.M., Miller, B., Funk, M., Morrow, E. (2021) The Modern Character of Mental Health Stigma: A 30-Year Examination of Popular Film. Communication Studies 72 (4). Routledge: 668-683. 10/ gm3rzh.

Schulenberg, J.L. (2016) Police Decision-Making in the Gray Zone: The Dynamics of Police-Citizen Encounters with Mentally Ill Persons. Criminal Justice and Behavior 43 (4). Sage Publications Sage CA: Los Angeles, CA: 459-482. 10/f8hbtb.

Shek, O., Ilkka, P. (2017) The Views of Family Caregivers on the Deinstitutionalisation of Psyhiatric Care in Russia. The Journal of Social Policy Studies, 15 (1). 10/ghq4gh.

Simonsson, P., Farwell, M.M., Solomon, P.L. (2020). Judicial Perspectives on Mental Health Courts: The Role of Psychiatric Disorder and Violence Risk. International Journal of Law and Psychiatry, 70 (May): 101562. 10/gkgjg9. 
Skeem, J.L, Polaschek, Devon LL, Patrick, C.J., Lilienfeld, S.O. (2011) Psychopathic Personality: Bridging the Gap between Scientific Evidence and Public Policy. Psychological Science in the Public Interest, 12 (3). Sage Publications Sage CA: Los Angeles, CA: 95-162. 10/fqp377.

Steury, E.H. (1991). Specifying Criminalization of the Mentally Disordered Misdemeanant. J Crim L \& Criminology, 82. HeinOnline: 334 . 10/dq49sj.

Tuliao, A.P. (2021) Public and Private Stigma, and Help-Seeking Intent for Mental Health Issues: A Cross-Country Comparison between the U.S. and Philippines. Stigma and Health. US: Educational Publishing Foundation, No Pagination Specified-No Pagination Specified. 10/gm3rzv.

Vlasova, O. (2014) Antipsikhiatriya: Sotsial'naya Teoriya i Sotsial'naya Praktika. Higher School of Economics.

Werner, P., Doron, I (Issi). (2017) Alzheimer's Disease and the Law: Positive and Negative Consequences of Structural Stigma and Labeling in the Legal System. Aging \& Mental Health, 21 (11). Routledge: 1206-1213. 10/gm3rz9.

Young-Anawaty, A. (1978) International Human Rights Norms and Soviet Abuse of Psychiatry. Case W Res J Int'l L 10. HeinOnline: 785.

Publisher's Note Springer Nature remains neutral with regard to jurisdictional claims in published maps and institutional affiliations. 